\title{
Urban flood control policy for sustainability under global warming in Japan
}

\author{
Y. Kawata \\ Research Center for Disaster Reduction Systems Disaster Prevention \\ Research Institute, Kyoto University, Japan
}

\begin{abstract}
Under rapid urbanization, any conventional flood control measure is no longer sufficient for class-A rivers in Japan. In answer to this problem, the construction of high specification levees (super levees) began in 1987, initially along especially important class-A rivers. This construction method involves restricting the slope on the city side of the levee to a gentle gradient of approximately $1 / 40$ so as to prevent the levee from breaking when flood water flows over the levee. Meanwhile, smaller rivers, known as urban rivers, have been the subject of a method of dealing with urban water disasters using comprehensive flood control strategies that were adopted at the end of the 1970s. After witnessing incidents of localized torrential rain throughout the nation caused by global warming since around 1995, it was clear that changes needed to be made to these flood control measures. Changes were necessary because the rainfall was so extreme that in many cases inundation inside the levee and by river water began occurring simultaneously, and because the inundation of both cities and rivers increased in scale. Of particular concern was the possibility of flooding in urban areas leading to the flooding of subterranean spaces. The "Urban Rivers Anti-Flood Measure Act" was implemented in April 2004 in response to the frequent occurrence of this kind of urban flooding with the aim of reducing flood damage in urban areas.
\end{abstract}

Keywords: urban flooding, urban river, torrential rain, global warming, urban flood control, disaster management, disaster reduction strategy. 


\section{Introduction}

Since the 1923 Great Kanto Earthquake, Japan has advanced disaster prevention measures by using civil and construction engineering to enable the erection of buildings and structures that will not collapse in earthquakes, and the construction of levees that do not flood. Although the human cost resulting from disasters has been reduced, direct and indirect costs including economic losses have continued to increase sharply every year, especially since the period of high economic growth. For example, flooding from torrential rains in the Tokai area in 2000 resulted in the loss of only 10 lives, but caused damage amounting to 900 billion yen in Aichi Prefecture alone. At approximately 280 billion yen, damage to housing and household goods amounted to about $30 \%$ of the overall costs. Other costs, such as the 100,000 cars written off due to water disasters and damage to expensive numerically-controlled machines on the first floors of flooded factories, would not have been conceivable in the past. In Japan, it is becoming increasingly inappropriate to express the scope of a disaster purely in terms of its human cost. The forms that damage takes have become more complex, and the majority of these types of damage can not be avoided with "information". Moreover, in every big city, we have large scale underground spaces for shopping malls and public streets connected by subway systems. Most of them are located in flood-prone areas, so the flood risk has increased year by year due to urbanization as well as global warming.

\section{Why the need for a shift from disaster prevention to disaster reduction?}

Japan's basic stance on disaster prevention measures was decided after the 1923 Great Kanto Earthquake. The earthquake spurred the introduction of strategies based on the construction of buildings and structures that do not collapse in earthquakes. This policy was also adopted for wind and flood disasters. The first serious efforts to formulate flood control plans began in the early Showa Period (1930s) with the development of plans based on the largest recorded floods. The policy had been applied before the Ise Bay typhoon disasters in 1959. After this period, with regard to wind and flood disasters, probability-based concepts were introduced into estimated high water discharge, and flow revisions were achieved through the lengthening of return periods. Return periods as long as 200 years are currently set for class-A rivers (in Japan, 109 river systems are controlled directly by the Ministry of Land, Infrastructure and Transport, MLIT) such as the Tone River and the Yodo River. However, in Japan, flawed land use plans implemented in the period of high economic growth resulted in rapid urbanization in the form of housing developments in river basins near big cities. This has led to the frequent occurrence of flooding in urban areas as shown in Fig. 1. Characterized by 1) increased peak discharge during flooding, 2) early peak flooding and 3) increased total discharge, this type of flooding means that conventional flood control measures are no longer sufficient for class-A or class$\mathrm{B}$ rivers $(2,722$ river systems are managed by governors in prefectural 
government). In answer to this problem, the construction of high specification levees (super levees) has begun, initially along especially important class-A rivers. This construction method involves restricting the slope on the city side of the levee to a gentle gradient of approximately $1 / 40$ so as to prevent the levee from breaking when flood water flows over the levee. Meanwhile, smaller rivers, known as urban rivers, have been the subject of a method of dealing with urban water disasters using comprehensive flood control strategies that were adopted at the end of the 1970s.

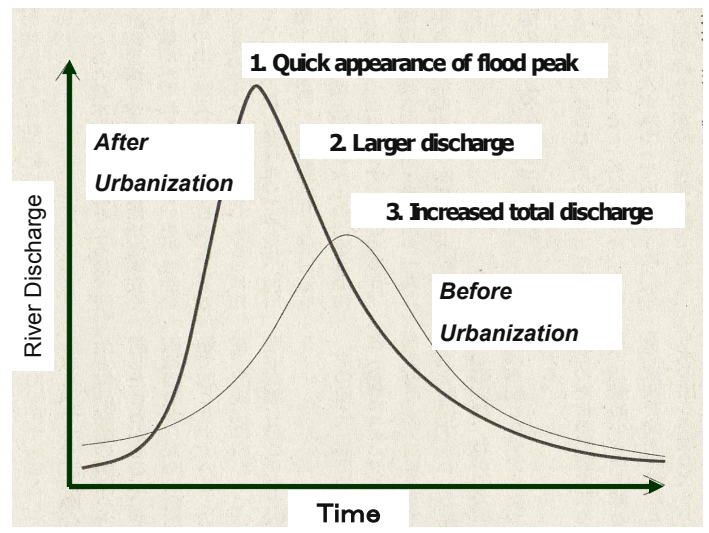

Figure 1: Changes of hydrograph due to urbanization.

After witnessing incidents of localized torrential rain throughout the nation caused by global warming since around 1995 as shown in Fig. 2, it was clear that changes needed to be made to these flood control measures.

Changes were necessary because the rainfall was so extreme that in many cases inundation inside the levee and by river water began occurring simultaneously, and because the inundation of both cities and rivers increased in scale. Of particular concern was the possibility of flooding in urban areas leading to the flooding of subterranean spaces. The flooding of "Deitos", an underground shopping mall at JR Hakata Station in Fukuoka City in 1999 and 2003 symbolized of this type of disaster. The "Law on Flood Disaster Mitigation Measures for Specific Urban Rivers" was implemented in April 2004 in response to the frequent occurrence of this kind of urban flooding, with the aim of reducing flood damage in urban areas. Responding to the fact that in many cases urbanization poses difficulties for the maintenance and improvement of water courses in cities, this law was formed with the objective of implementing measures in these places in an integrated way. Then, for the first time in history, it was shown that urban flooding caused by extreme rainfall cannot be reduced to zero. Figure 3 shows the damage caused by localized torrential rain and typhoons in 2004. The disasters claimed 202 Japanese lives. Around twice as many males died than females, and the frequency of outdoor deaths was about twice as high as those that occurred indoors. About $60 \%$ of all deaths were seniors. 

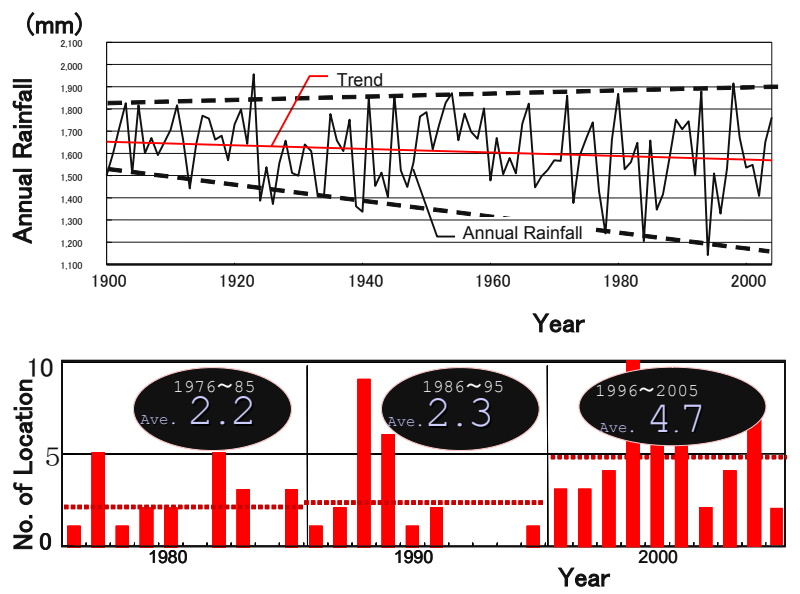

Figure 2: Changes of annual rainfall (upper) and number of AMeDS locations that recorded more than $100 \mathrm{~mm}$ /hour (lower) (AMeDS: Automated Meteorological Data Acquisition System controlled by the Japan Meteorological Agency at about 1,300 locations in our country since 1970).

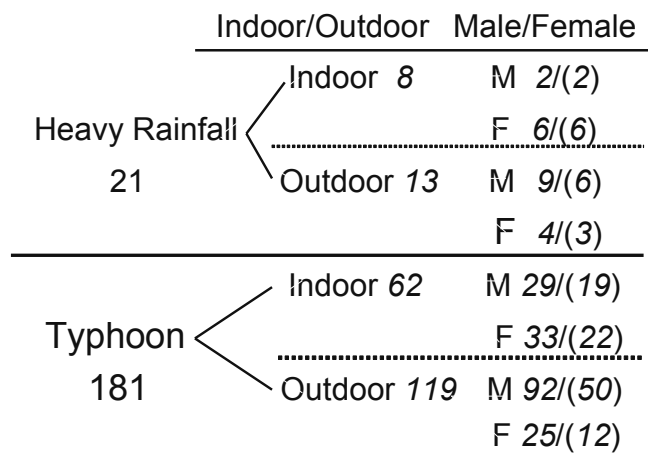

Figure 3: Number of victims due to storm disasters in 2004 (number in brackets shows elderly people at the age of more than 65 years old).

Among those seniors, most men died outdoors, while most women died indoors when they drowned after missing a chance to escape. While most deaths during recent wind and flood disasters were of seniors, new types of casualties are increasing.

Reviewing these events, one is able to understand how much seismic and flood control concepts have changed since the 1995 Great Hanshin-Awaji (Kobe) Earthquake. This change is a change from "disaster prevention" to "disaster reduction". Put simply, "disaster reduction" is "preparing responses based on the assumption that damage will occur, and working to minimize that damage." 


\section{What are urban flood disasters?}

Whether a flood results in urban flood damage or not depends on whether the extent of the damage was properly predicted. It follows that the biggest reason that it is difficult to predict the extent of damage is that our cities have changed over the years and our damage predictions cannot keep up with these changes. In particular, underground spaces in major cities are being exploited more extensively, and all of these underground spaces are located in flood-prone areas. Once a major flood strikes one of these areas, it is difficult to imagine the whole picture of possible damage. This leads to urban flood damage. The structure of cities in Japan started to change drastically since the 1990s. Precipitation patterns have also changed drastically over these years due to global warming.

Although almost all recent flood disasters in Japan is urban-type flood disasters, there are significant differences between the circumstances of individual cases as shown in annual reports by MLIT [1]. One group of cases occurs when a large amount of precipitation occurs during a short period of time in a relatively small geographic area, such as in the torrential rains that struck Niigata and Fukui in July 2004, when almost $100 \mathrm{~mm}$ of rainfall was recorded within one hour. In these cases, river levees collapse, resulting in a flood (called an inundation by river water) or urban areas are flooded with water that exceeded the amount of water manageable by the city (called an inundation inside a levee).

Another group of cases occurs when hourly precipitation of 30 to $40 \mathrm{~mm}$ falls over a large area of a drainage basin for a prolonged period of time, such as six hours. An example of this is when Typhoon No. 23 in October 2004 brought heavy rains that overflowed the Maruyama River. The collapse of its main river dyke flooded $90 \%$ of the urban areas of the City of Toyooka. Another example is a flood of the Yura River in Kyoto Prefecture that occurred under the same conditions. Each of these rivers has a drainage basin exceeding 1,000 square kilometers. Major contributing factors in these cases were that heavy rain due to Typhoon No. 23, a large typhoon, covered a large area, and that the typhoon moved relatively slowly.

\section{Future measures to prepare for urban complex flooding}

It is becoming necessary to provide anti-flood measures to city cores that cover both above and underground locations. In Japan, we have many underground shopping molls and subway systems in big cities such as Tokyo and Osaka. The total area is more than 100ha. Most of all are expanded in flood prone areas. Such comprehensive measures are not easy to provide because of conflicting interests. Therefore, we first discuss anti-flood measures above ground in the city center. The Urban Rivers Anti-Flood Measures Act came into force in April 2004, with the purpose of alleviating flood damage in urban areas based on features specific to urban flood disasters. In particular, because it is often 
difficult to improve riverside roads due to urbanization in city centers, this act was enacted to provide comprehensive measures against flood.

This act is designed so that external water overflow and internal water overflow floods will be addressed holistically taking into account recent frequent occurrences of unusually severe torrential rain. Thanks to this act, cities, townships and villages share responsibility for flood prevention measures unlike before. Previously, these cities, townships and villages were directly benefiting from regional development, while prefectures paid for the development and covered the damage from disastrous outcomes. This distorted flood-management system has been corrected by the Act. However, it is foreseeable that designating a river as an urban river for the purposes of the Act will cause cities, townships and villages to share responsibility. Issues Concerning Anti-Flood Measures in Underground Spaces

In recent years, water disasters to underground spaces has occurred more frequently. Some of the measures needed to prevent such damage and the issues surrounding that damage is presented below based on the survey results concerning several flood cases.

\subsection{Item extraction and analysis}

To examine the flood disaster management system for underground spaces, we first analyzed past survey results to identify the current status of anti-flood measures and issues concerning underground spaces. We then extracted the preparation needed to reduce the flood damage. To analyze the current status of and issues surrounding anti-flood measures, we looked at the survey results in four major categories: prevention, preparation, response and recovery. The results are shown in Fig. 4 and every problem is briefly explained in 5.2 to 5.5 as following.

\section{- Flood Forecasting}

In a pre-disaster stage, 6 problems $(5.2 .1 \sim 6)$ are included to verify hazard characteristics and hard-countermeasure maintenance.

\section{- Preparedness for Flood}

In a pre-disaster stage, 6 problems $(5.3 .1 \sim 6)$ are included to prepare insurance and information.

\section{- Anti-flood Measures}

In a post-disaster stage, 5 problems $(5.4 .1 \sim 5)$ are included to reduce direct and indirect damage.

\section{- Recovery Efforts}

In a post-disaster stage, 2 problems (5.5.1 and 2) are included to step up the recovery process.

Figure 4: Summary of past survey results on flood inundation in underground space. 


\subsection{Flood forecasting}

\subsubsection{The necessity of surveying and considering the disaster environment concerning floods}

The possibility of underground flooding appears to have been foreseen to some extent from the start, evidenced by the fact that most underground malls are equipped with sandbags and water-guard boards. On the other hand, there has been little risk information provided by different levels of the government so far, and underground mall management bodies have so far made their own assessments of flooding risk.

\subsubsection{The preparation and distribution of information to understand the disaster environment, such as hazard maps}

No underground mall management body determined their flood management plan and flood prevention activities based on hazard maps. Such bodies did say, "we would like to see the preparation and publication of hazard maps, and active disclosures of anti-flood measures concerning the overflow of major rivers." This indicates that there is a strong desire for disclosure and provisioning of various information such as hazard maps.

\subsubsection{The consideration and introduction of flood prevention equipment}

Based on the businesses in underground malls and the personnel on their management bodies, it will be extremely difficult to install any flood control equipment during a flood. To make it easier to install, equipment should be automated and lightweight.

\subsubsection{The necessity of the evaluation of flood management programs for underground malls}

The flood management programs for underground spaces are essentially an issue of the underground management bodies themselves. Such bodies are rarely evaluated or guided by the government or municipalities. Although people foresee the risk of an underground flood to some extent, it is difficult to determine how much flood risk is foreseen.

\subsubsection{The improvement of and publicity regarding financing and financial assistance for the introduction of flood prevention facilities}

Many management bodies are concerned about the cost of introducing anti-flood facilities. Publicity for and mediation with existing financing programs (such as the financing program of the Japan Development Bank) should be done as needed.

\subsubsection{The necessity of administrative guidance and information disclosure for underground space management bodies}

There has been little guidance from the government concerning anti-flood measures in underground spaces. However, when we conducted surveys, people said, "the government should provide specific information disclosure and guidance" and "the government should provide guidance to all management 
bodies that are connected through underground passageways." This indicates that such bodies expect government action. Future issues of concern regarding governmental guidance include: What guidance should be provided? (For example, should this guidance concern construction? fire?) There is also no wellestablished consent to whom this guidance should be provided.

\subsection{Preparedness for flood}

\subsubsection{Flood insurance}

Some insurance policies held by underground mall management bodies currently cover flood damage. However, most such policies do not clearly define what is covered. Quite a few underground business owners are concerned about what may be covered if they suffer large-scale flood disasters.

\subsubsection{Preparation of a flood management manual}

Quite a few underground space management bodies would like the government and municipalities to provide information and specific guidance for their flood management programs so that such programs can become more specific and realistic.

There are other issues concerning setting up flood management programs and preparing flood management manuals: 1) Underground business owners must coordinate with evacuation sites that are connected through entrances to the underground spaces., 2) Underground business owners and users need further disaster management education., 3) Underground spaces must practice worstcase scenario flood-disaster drills., 4) Personnel should be secured in the case of an emergency (including emergencies at night and on holidays).

\subsubsection{Information disclosure on infrastructure improvements and flood control measures}

Underground flood disaster prevention measures cannot be dealt with only by the underground space management bodies. Our survey indicates that many people were of the opinion that necessary disaster prevention measures can be determined according to the responsibility of different levels of government for flood management. We can see people demand considerable information disclosure on infrastructure improvement and demand significant flood control progress.

\subsubsection{Clarification of the position of underground anti-flood measures as part of the urban disaster management program}

Anti-flood measures are not clearly positioned in relation to other urban disaster management initiatives. Ant-flood measures conflict with other initiatives (such as the effort to remove steps at entrances to remove barriers for handicapped access). Some management bodies pointed out the need for administrative guidance and information disclosure when they apply for a building permit.

\subsubsection{Education on basic knowledge concerning urban flood}

Most people think of earthquakes when it comes to urban disasters. However, some people said that flood information should be taught at schools, etc. in the future. 


\subsubsection{Improvement in the accuracy of flood forecasting}

As we discussed earlier, workers on flood relief duty are most anxious about the collection of information. Also, to respond to floods more quickly, many desired an improvement in flood forecast accuracy.

\subsection{Anti-flood measures}

\subsubsection{Determining the appropriate anti-flood measures according to the degree of risk}

Some underground space management bodies were implementing anti-flood measures based on the degree of risk expected. This resulted in some groups assembling water-guard boards and sandbags closer to where they are to be installed in the case of a flood rather than storing all such equipment together. In preparation phase for actual installation, pre-assembling equipment and placing materials closer to their installation point helps mitigate flood risk but is partly a response to inadequate manpower for flood rescue operations.

\subsubsection{Securing the safety of tenants and users}

The following are issues concerning securing the safety of tenants and users of underground malls. 1) How to alleviate panic, 2) How to coordinate with and secure evacuation sites above ground, 3) How to provide assistance to vulnerable people in case of a disaster.

Some respondents pointed out in our survey that an issue concerning the evacuation of users is how we convey and express evacuation information. Unless we do it right, we may cause panic. Therefore, some management bodies are actively considering the issue of how we impart evacuation information.

\subsubsection{Providing information that supports evacuation decisions}

There is a strong desire to make the disaster information easy to understand. Instead of providing unlimited information, people desire immediately relevant information that is directly related to important decisions (such as when businesses will reopen, and evacuation guidance) and guidance directly from the authorities. For instance, we heard the following opinions in our survey.

\subsubsection{Coordination between related organizations across a large area}

In many cases, it is not possible to prevent water from flowing into an underground space through the action of one entity's anti-flood measures alone. Water will flow from one underground space to connected spaces, and it can require multiple entities to secure an evacuation site. For this reason, many groups surveyed said that it is necessary to provide specific procedures that cover a large area for underground flood management.

\subsubsection{Providing assistance to people who cannot easily return home}

In past floods, such as Tokai Heavy Rainfall Disaster in 2000, providing assistance to people who are left behind at places like train stations was a major issue. Even if each underground management body has its own flood countermeasures, they may not receive sufficient support because they are not 
officially included in the regional disaster management programs of municipalities. In our survey, some groups would like to assist people who cannot return home easily using clear directives and resources from a regional disaster management program.

\subsection{Recovery efforts}

\subsubsection{Various issues of coordination regarding the procurement of recovery equipment and materials}

In the unlikely event that an underground space is submerged under water, large scale pumping operations are required for recovery. However, because each management body does not own such equipment itself, people responded in our survey that the government (especially fire departments and the regional offices of MLIT) should respond quickly with coordinated efforts.

\subsubsection{Financial assistance for the reopening of businesses}

All underground mall management bodies wonder if financial assistance is available for reopening their businesses after a flood.

\section{Conclusion}

We have reviewed the reality of floods, a disaster the frequency and severity of which is expected to increase, and flood damage-reduction plans. First, we reviewed the characteristics of natural disasters due to strong winds and floods in 2004, and pointed out that seniors are most strongly affected. We then discussed the Urban Rivers Anti-Flood Measures Act that came into force in April 2004. The law was implemented in response to the frequent occurrence of this kind of urban flooding with the aim of reducing flood damage in urban areas. For the first time in Japan, it was shown that urban flooding caused by extreme rainfall can not be reduced to zero. We introduced the changes of policy on urban flood control and perspective on the balance with earthquake disaster reduction policy.

\section{Reference}

[1] River Bureau, Ministry of Lifeline, Infrastructure and Transport, Assessment of disaster manages in 2001, 2002, 2003, 2004, 2005, 2006 and 2007 (in Japanese). 